Motrivivência Ano XXII, No 34, P. 87-105 Jun./2010

DOI:10.5007/2175-8042.2010n34p87

\title{
AS TECNOLOGIAS: do software livre às experiências com a Educação Física e Mídia
}

\begin{abstract}
Resumo
Este estudo analisou as dimensões educacionais das tecnologias sem abrir mão dos aspectos políticos, econômicos, sociais e culturais. Atribuiu o sentido do Software Livre a uma perspectiva de mudança no ato de ensinar-aprender a lidar com as tecnologias e mídia. Correlacionou vários campos do conhecimento, da comunicação e mídia, especificamente a partir de experiências/pesquisas na educação física. Aponta para dimensão crítica-reflexiva do uso das tecnologias na educação no sentido de socializar este bem que é fruto da construção humana.

Palavras-Chave: Tecnologia; Mídia; Educação Física.
\end{abstract}

\begin{abstract}
This study examined the education dimensions of technology, without disregarding the political, economic, social and cultural aspects. We attribute the meaning of free software to the prospect of a change in the acting of teaching-learning to deal with the technologies and media. We correlate several fields of knowledge, of communication and media, specifically from experience/research in Physical Education. We point to a critical-reflexive dimension of the use of technology in education, in a effort to socialize this, that is the result of human construction.
\end{abstract}

Key-words: technology, media, Physical Education.

1 Professor Assistente do DEF/UFS. Mestre em Educação Física/UFSC. Doutorando do Programa de Pós-graduação em Educação da UFBA. Pesquisador FAPESB. Membro do Observatório da Mídia Esportiva (UFSC/UFS) e do Grupo de Estudo e Pesquisa em Mídia/Memória, Educação e Lazer (MEL/UFBA). Contato: dorenski@gmail.com. 


\section{Introdução}

Não muito tempo, mas a configurar-se enquanto uma possibilidade contra-hegemônica aos ditames da indústria midiática, bem como aos exageros do controle do conhecimento e da informática - no tocante a produção imaterial de produtos e bens - surge uma "corrente" em que, o mais importante na cultura das redes informacionais e na utilização dos bens imateriais, é a socialização, o compartilhamento e sua disseminação do conhecimento através das redes. Esta corrente é o software livre (SL).

Numa época em que se torna quase impossível estar sem as Tecnologias ${ }^{2}$ de Informação e Comunicação $\left(\text { Tic's }^{3}\right)^{3}$ seja na vida cotidiana, seja no campo profissional e em especial na educação, as políticas (públicas) de acesso a elas são poucas. Até por que a tecnologia não é neutra e é fruto da interação das forças sociais, econômicas, políticas e culturais (BRANT, 2008). No entanto, numa economia sob a dominação do dinheiro percebe-se quanto este poder impede a emancipação dos sujeitos. A confrontação, a partir de uma economia da dádiva, com práticas sóciotécnicas para enfrentar e desmanchar a concentração de riqueza e poder tem sido a luta de vários "guerreiros" Hackers $^{4}$ - no intuito de publicizar os bens produzidos culturalmente pela humanidade.

A criação do software livre provoca uma mudança significativa na relação com a disseminação do conhecimento, pois qualquer pessoa pode adquirir sem nenhum custo, ou seja, constitui-se em um uso comum. Como expõem Simon e Vieira (2008, p. 22),

a idéia de 'uso comum', no caso do software livre, foi elevada a

2 Incluem-se também as digitais e sua relação com a mídia. Entendo que há distinção entre a Mídia e Tecnologias, no entanto, aqui a sua dimensão política e educacional é o ponto principal para reflexões e neste sentido, aparecem, neste artigo, de forma semelhante pelo potencial criativo que provocam.

3 Usarei abreviadamente desta forma, pois sei que há aqueles mais tradicionais, para não dizer positivistas, que dizem em sigla não se usa o plural. No entanto, foi assim que aprendi, carinhosamente, a lidar com a mídia e as tecnologias. Recordo das boas aulas dos professores Lucídio Bianchetti e Giovani Pires nas disciplinas, respectivamente, Educação, Trabalho, Novas Tecnologias de Informação e Comunicação (CED/PPGE/UFSC) e Educação Física, Esporte e Mídia (CDS/PPGEF/UFSC) no ano de 2003; bem como, a mensagem da professora Mary Arapiraca PPGE/UFBA - Disciplina Projeto de Tese II (2010) - em que "as palavras vão criando vida e autonomia".

4 Para Himanen (2001), Hackers são indivíduos que se dedicam com entusiasmo à programação. Acreditam no compartilhamento de informações, bem como facilitar o acesso a elas, por isso, elaboram softwares livres. 
um patamar superior; não só o uso propriamente dito dos programas é livre e comum, mas também o seu desenvolvimento: todos podem ter acesso à estrutura interna dos programas e modificá-los como bem entenderem [...].

Esta característica é a matriz geradora do processo de sociabilização em rede, ao mesmo tempo em que várias pessoas constroem os programas, possibilitam que o custo final seja zero. Isto é o que diferencia da lógica capitalista das instituições fechadas na qual o custo é repassado aos consumidores. Portanto, o debate e ação política sobre este campo não podem ser mais em um plano individual, pois afeta um interesse que é coletivo.

Na educação, percebe-se o quanto este campo é marcado pela lógica competitiva e isto ocorre há décadas. Talvez, a experiência explicitada por Benkler (2010) na construção de material didático (livro didático) em pares (professores e demais membros da sociedade), na idéia da produção social em commons $^{5}$, na perspectiva colaborativa do SL seja uma boa subversão para quebrar a esfera comercial que configura o mercado da informação e comunicação em rede. No entanto, esta ação precisa ser estimulada e criada a "cultura" do compartilhamento, pois, considero importante o alerta de Brant (2008, p. 70), no que se refere a batalha da competição e da colaboração na área educacional:

[...] pode ser instrumento que propicia condições para a conquista da autonomia política ou pode, na segunda face da mesma moeda, ser simplesmente o aparelho ideológico do Estado em que se reproduz a ideologia dominante.

As Tic's têm um papel significativo no atual contexto da sociedade contemporânea. Ao mesmo tempo em que elas nos aprisionam - pois é quase impossível viver sem - elas nos possibilitam a liberdade, a ousadia de fugir às regras e principalmente, a autonomia do sujeito. Trata-se então, da necessidade de criar possibilidades de sair da aporia que nos é colocado na sociedade.

Assim, pretende-se aqui estabelecer uma relação entre o "sentido" dos softwares livres na

5 Esta ação é baseada numa ação fora do mercado, no uso da informação disponível em domínio público. Ninguém tem direito exclusivo e libera seus produtos de volta para o mesmo commons. (BENKLER, 2010). 
conjuntura político-social-econômica contemporânea e sua inserção às tecnologias móveis e como este "sentido" pode estabelecer nexos com outras práticas, outras áreas e em especial a Educação Física. Para isto, buscou-se estabelecer um diálogo entre diversos autores que tem como objeto de estudo as tecnologias e a mídia na contemporaneidade, bem como, trazer experiências no âmbito da Educação Física neste campo.

Entende-se que a presença das tecnologias - digitais - de informação e comunicação constitui-se uma realidade indiscutível na cultura contemporânea. Querendo ou não, nos relacionamos - com elas - em diversos campos da vida, seja em casa, no trabalho, na comunicação entre as pessoas, no campo acadêmico/científico, enfim, o cotidiano já esboça a sua presença o que, aparentemente, provoca uma naturalização delas. Os estudos no campo da Educação Física e do Esporte que se entrelaçam com as tecnologias ainda aparecem de maneira tímida. Neste estudo, a contribuição é no sentido de ratificar as ações de pesquisadores neste campo e estender o convite para que se pense em ações permanentes no âmbito escolar. Com isto, abrir e publicizar o debate para sociedade.

Portanto, iniciarei uma discussão sobre as Tic's e sua dimensão política, econômica, cultural, social e principalmente, colaborativa. Bem como, a perspectiva de síntese entre as tecnologias de comunicação (convergência) a partir do celular. Por último, uma reflexão de experiências da Educação Física neste campo.

\section{As Tecnologias e sua Dimen- são Político-Cultural}

As tecnologias - Tic's constituem-se parte significativa na atual conjuntura social contemporânea $^{6}$, seja no mundo do trabalho, do conhecimento, do entretenimento, ou simplesmente nas redes de relacionamentos. Fica evidente que as Tic 's reinauguram uma nova linguagem na contemporaneidade e, com isto, traz novas narrativas na sua gênese bem como, esboça relações de poder que caracterizam as ideologias presentes, portanto, elas têm um valor significativo, resultante das forças sociais, econômicas e políticas, que caracteriza sua não-neutralidade.

6 No programa "Canal Livre" - da TV Bandeirantes - exibido em 21/03/2010, cuja temática central de discussão era as tecnologias (digitais, informação e comunicação), o apresentador Joelmir Betting, ratifica ao dizer que elas estão presentes em todos os ramos da sociedade. Obviamente que temos clareza de seu valor, mas quando uma emissora aberta e comercial provoca a discussão, precisamos - educadores - estarmos atentos. 
Para Kenski (2007), tecnologia é poder. Talvez, este tenha sido o grande motivo da luta pelo seu domínio, ou seja, dominar a tecnologia significa dizer estar à frente dos outros. Foi assim desde os tempos mais remotos - na guerra do fogo, na construção dos artefatos de pau e pedra, da guerra espacial, até o domínio das mais sofisticadas tecnologias na atual sociedade - e continuará por muitas décadas até que se mude a concepção de sua "posse".

Não resta dúvida que a relação entre conhecimento, poder e tecnologias marcaram tempos passados e presente. É notório o quanto relacionamos as sociedades, sejam elas mais primitivas ou modernas, a um tipo de tecnologia e conhecimento. Foi assim com a idade da pedra, a fase dos metais - ouro, prata e bronze - do próprio período industrial, marcado pela invenção da máquina (vapor e ferramenta) $)^{7}$ e hoje caminha-se para uma sociedade da informacional ${ }^{8}$, ou melhor, uma sociedade em rede. A máxima de Francis Bacon ${ }^{9}(2000)$ em que "saber é poder" nunca ficou tão evidente. Para este filósofo o conhecimento científico e experimental serviria para um bem-estar e harmonia dos homens. Então, apesar das tecnologias, como expõe Kenski (2007), invadirem nossas vidas, ampliarem nossa memória, garantir o nosso bem-estar, elas ainda estão longe de serem socialmente distribuídas, devido ao poder, seja ele, econômico, político ou simbólico ${ }^{10}$ (THOMPSON, 1998).

O poder, aqui simbolizado pelas tecnologias, é fruto da capacidade - intelectual - humana e que, portanto, como alerta Kenski (2007) não são apenas máquinas, a exemplo da linguagem. A Tecnologia perpassa esta dimensão, pois ela está em todas as partes das nossas vidas. Ou seja, ela é o "conjunto de conhecimentos e princípios científicos que se aplicam ao planejamento, à construção e

7 O motor a vapor, que é chamado de máquina a vapor costumeiramente refere-se também a turbina a vapor outro tipo de máquina térmica que exploram a pressão do vapor. Todas as máquinas térmicas funcionam baseadas no princípio de que o calor é uma forma de energia, ou seja, pode ser utilizado para produzir trabalho, e seu funcionamento obedece às leis da termodinâmica. A máquina ferramenta, também chamada de máquina operatriz, é uma máquina utilizada na fabricação de peças de diversos materiais (metálicas, plásticas, de madeira etc.), por meio da movimentação mecânica de um conjunto de ferramentas. (www.wikipedia.org). Acesso em: 04/10/2010.

8 Ver Castells (1999).

9 (1561 a 1626, nascimento e morte, respectivamente).

10 Thompson (1998), a partir do pensamento de Pierre Bourdieu, explica há quatro dimensões do poder: Político - representado pelas instituições públicas; Coercitivo, as instituições militares e a força bélica; Econômico, instituições econômicas (empresas) marcado pelos oligopólios dos conglomerados econômicos e o Simbólico - Instituições culturais, igreja, indústria da mídia entre outros. 
à utilização de um equipamento em um determinado tipo de atividade" (Op.cit., p.24).

O homem passa a (re) projetar sua relação com a tecnologia, pois nunca na história humana esta relação foi tão determinante. São chips implantados no cérebro recuperando movimentos perdidos, são próteses dos mais variados tipos, são invenções tecnológicas de forma mais determinante que deixaria Aldous Huxley"11 "admirado", a exemplo das pílulas da juventude ${ }^{12}$ o que provoca um "deslumbramento" nas pessoas.

Por outro lado, tenho clareza que isto não representa uma homogeneidade dos acessos aos bens, mas configura-se como um indicativo e acredito de forma inevitável e não freada. Não se pode parar o avanço tecnológico, no entanto, é preciso sociabilizar mais as invenções, pois, parece-nos que elas ainda estão no plano tão somente do espetáculo/mercadoria e da comercialização.

No campo educacional, sua inserção é uma "viagem sem volta". Não se pode mais conceber a apreensão do conhecimento alunos e professores - sem a devida apropriação das tecnologias, até por que elas já estão presentes em suas vidas. No entanto, as políticas públicas de acesso às tecnologias, no campo educacional, ainda carecem de ações mais corajosas. Aqui cabe o alerta de Pretto e Assis (2008) em que o computador, o rádio a $t v, a$ internet e as mídias digitais, devam estar inseridas no ambiente escolar e com isso, a escola (professor, aluno, entre outros) passe a constituírem-se em produtores de cultura e conhecimento. Esta perspectiva possibilita caminhar para outro lado e com isso, ao invés de estarmos preparando a sociedade/escola para um mero consumo (até que possa existir), mas, principalmente na perspectiva de formar cidadãos, produtores de sua própria cultura e que esta seja compartilhada com os demais sujeitos em redes de colaboração, ou seja, se institui um pensar coletivo, uma inteligência coletiva.

A idéia baseia-se nas redes de colaboração e no uso de Software Livre (SL), mas afinal o que é SL? Constitui-se em software

11 Aldous Huxley, autor do clássico "Admirável Mundo Novo" - publicado em 1932 - que simboliza uma sociedade futurista e dominado pela técnica em que até as sensações são estimuladas artificialmente, ou seja, as pessoas são condicionadas biologicamente e psicologicamente a viverem em harmonia segunda as regras sociais vigentes.

12 Constitui-se numa promessa para retardar a velhice. É um comprimido de silício orgânico e traz vitalidade aos tecidos da pele, das unhas e aos cabelos. O silício orgânico tem a função de regenerar as células da pele. Disponível em: www.colmeia.blog.br. Acesso em: 22/04/2010. 
aberto - código aberto - significa dizer que há um "uso comum", ou seja, "não só o uso [...] é livre e comum, mas também o seu desenvolvimento: todos podem ter acesso à estrutura interna dos programas e modificá-los [...]" (SIMON E VIEIRA, 2008 p.22). Esta idéia constitui-se em práticas colaborativas, que gera novas possibilidades de comunicação e mais que isto, descentraliza o poder vertical (de cima para baixo) gerando a horizontalização das ações é como se víssemos a "massa" no processo criativo do conhecimento de forma democrática. Além disso, uma das características mais importante do SL é quebrar a lógica da informação como mercadoria, bem como desfazer a lógica comercial (BRANT, 2008).

Para Tas (2008, p. 206) o SL tem como beleza "estimular a colaboração entre os seres humanos [...]. Cada uma das pessoas envolvidas está com o foco no aperfeiçoamento de uma idéia". Neste sentido, vejo no SL a possibilidade revolucionária de sociabilização das produções humanas no campo das tecnologias. Quanto mais se compartilha o conhecimento, mas ele cresce. Assim, garantir o compartiIhamento ao software, "é essencial para construção de uma sociedade livre, democrática e socialmente justa" (SILVEIRA, 2004, p. 7).

Evidentemente, que o Software Livre pode ser comercializado se houver interesse, no entanto, ele não é propriedade de alguém, a exemplo do software proprietário (baseado em licenças restritivas de uso). O SL caminha no sentido contrário, ou seja, a única restrição é a não restrição, com isso, a liberdade de usá-lo é sua essência e, portanto, não se configura numa relação de preço (Op.cit.,).

Ao fugir da esfera eminentemente consumista e da lógica do dinheiro, encontra-se uma possibilidade que, se estimulada e apoiada pelas instâncias públicas, pode provocar um novo modo de ver o mundo e suas relações.

\section{Do celular às convergências: Possibilidades narrativas!}

"A convergência representa uma mudança no modo como encaramos nossas relações com as mídias" (JENKINS).

Cada vez mais vamos perdendo ou substituindo os processos de interação face à face (THOMPSON, 1998) por processos tecnológicos de interação mediada, pois esta cria novas formas de relacionamentos sociais bem diferentes do passado da história humana. De uma simples carta escrita à mão, passamos para correio eletrônico, mensagens via celular, 
relacionamentos que representam o "imediatamente agora". Isto, ajudado pelas redes de comunicação via satélite, que (re) configuram a relação espaço-tempo.

Além disso, o impacto dessas mudanças gera outras necessidades. Assim, os equipamentos tecnológicos de comunicação são cada vez menores e mais potentes e ainda converge para si, uma diversidade de mídias. Por isso, encontramos hoje em um só aparelho celular, as funções de correio eletrônico, televisão, internet, videogame, rádio, câmara fotográfica e de filmar e uma série de outras funções.

O termo convergência refere-se ao fluxo de conteúdos através de múltiplas plataformas de mídia, à cooperação entre múltiplos mercados midiáticos e ao comportamento migratório dos públicos meios de comunicação (JENKINS, 2009), ou seja, não é só uma mudança significativa do uso das tecnologias a partir de um só aparelho, mas, sobretudo, uma mudança de comportamento, de estar no mundo. A interação cada vez mais flui por diversos canais imprevisíveis.

Quando surgiu, o celular ${ }^{13}$ parecia um simples aparelho com a função de comunicar-se fora de casa ou do trabalho, algo bem modesto. Em pouco tempo tornou-se uma das mídias mais usadas no planeta. Para Tas (2008, p. 203) "a telefonia fixa ficou para trás [...]. A tendência para o futuro aponta a telefonia móvel crescendo mais que a internet". Entendo que esta tendência é uma resistência ao modelo ainda vigente da internet, pois a partir do instante que o celular estiver ao alcance de todos e ao mesmo tempo convergir a maioria as mídias, ele sobressairá sobre as demais, o que já estar acontecendo em pequena escala mas, já coloca o note book como uma tecnologia muito grande e às vezes, de difícil locomoção.

Nesta perspectiva é que se observa o celular também em rede de colaboração - já há invenções com Software livre ${ }^{14}$ - e isto pode significar uma maior amplitude de acesso pela diminuição de preço ao produto final, ou melhor, mais pessoas utilizarão esta mídia, que a meu ver, é a que mais simboliza a função da convergência tecnológica. Como expõe Jenkins (2009, p. 42),

Boa parte do discurso contemporâneo sobre convergência

13 Martin Cooper (Norte Americano, nascido em Chicago) inventou o celular nos anos 1970. www. softwarelivre.org. Acesso em: 22/04/2010.

14 Durante o Fórum Internacional Software Livre em Porto Alegre/RS (2008), já foram apresentados softwares para uso em celular. Folha Online. www1.folha.uol.com.br. Acesso em: 22/04/2010. 
começa e termina com o que chamo de Falácia da Caixa Preta. Mais cedo ou mais tarde, diz a falácia, todos os conteúdos de mídia irão fluir por uma única caixa preta em nossa sala de estar (ou, no cenário dos celulares, através de caixas pretas que carregamos conosco para todo lugar).

O que se presencia, portanto, é o surgimento de uma nova narrativa uma vez que passamos a relacionar - de modo nunca antes visto a partir das convergências de tecnologias e mídias - nossas vidas, numa dimensão de velocidade, espaço e tempo do "aqui e agora". O que para Lemos (2010) estaria no plano da desterritorialização, ou seja, compreender a cibercultura a partir de um pensamento móvel.

A convergência das mídias é mais do que apenas uma mudança tecnológica. [...] altera a relação entre tecnologias existentes, indústrias, mercados, gêneros e públicos. A convergência altera a lógica pela qual a indústria midiática opera e pela qual os consumidores processam a noticia e o entretenimento (JENKINS, 2009 p.43).
Neste contexto, significa uma mudança na lógica de como opera também os meios de comunicação, pois o "potencial consumidor" dispõe de um poder e ganha um espaço em participar intimamente da cultura. É possível então que as novas narrativas possibilitem um futuro mais livre em que os sujeitos - aqueles que sempre foram considerados meros consumidores - possam produzir cultura. "O público, que ganhou poder com as novas tecnologias e vem ocupando um espaço na intersecção entre os velhos e os novos meios de comunicação, está exigindo o direito de participar intimamente da cultura" (Op.cit., p. 53).

\section{Sobre a Educação Física [...] ou outras experiências!}

As Experiências que envolvem as Tic `s e a Educação Física ainda estão em um plano recente, mas que ao mesmo tempo, apontam para um campo vasto de inúmeras possibilidades. Explicitarei sobre alguns trabalhos ${ }^{15}$ - sem desmerecer nenhum outro e nem tampouco, nenhum outro grupo de pesquisa que me inspirou para reflexões:

15 Especificamente, referem-se aos produzidos pelo Labomídia - Laboratório e Grupo de Estudos Observatório da Mídia Esportiva/UFSC/UFS - Disponível em: www.labomidia.ufsc.br; acesso em: 06/09/2010. 
- Neste aspecto, a Dissertação de Mestrado de Marcio Romeu Ribas de Oliveira - "O Primeiro Olhar: Experiência com Imagens na Educação Física Escolar" - impressiona por "ousar e permitir", significa dizer que os atores sociais do campo de pesquisa, foram fundamentais para apropriação com reflexão acerca do uso das tecnologias no meio escolar, pois a pesquisa tratou da inserção de meios técnicos na produção de imagens no âmbito da Educação Física Escolar a partir da "cultura midiática"16 na qual os alunos da escola estavam envolvidos. $\mathrm{O}$ que resultou numa significativa mudança de olhar dos alunos (envolvidos à pesquisa), a partir da experiência com a fotografia e a produção de vídeo (OLIVEIRA, 2004);

- Por este caminho, observamos o trabalho de Cássia Fernanda Cardoso dos Santos - "A Mídia nas Aulas de Educação Física: Uma possibilidade" - Fruto de um trabalho monográfico (DEF/ UFS), cujo principal objetivo foi analisar a utilização dos recursos midiáticos (Tv, vídeo-cassete, câmera, máquina fotográfica entre outros), nas aulas de Educação Física. Na proposição da
Pesquisa com Observação Participante, resultou na criação e recriação da mídia na qual, em conjunto com os alunos, foram elaborados roteiros, jornal, filme, numa perspectiva autônoma e emancipatória dos envolvidos. É importante ressaltar a mudança de olhar dos sujeitos da pesquisa (alunos da escola) em relação à mídia. Como ela é elaborada, pensada e repensada na sua construção, ou seja, desvelando os segredos que o fetiche da mídia provoca em todos nós a exemplo da fala de um dos sujeitos da pesquisa:

Agora entendo como é feito a mídia, como a imagem chega à televisão, como os jornais e revistas são feitos e que não é como um passo de mágica, como parece ser (SANTOS 2007, p. 10);

- Cássia Hack - "Lazer e Mídia em Culturas Juvenis: Uma Abordagem da Vida Cotidiana" - Neste estudo, fica evidente que a relação Mídia e Lazer, pela perspectiva de Culturas Juvenis, e condição sine qua non para diagnosticar a construção de valores e comportamentos adotados numa sociedade de consumo, produzida pela industrialização

16 Vista como produtora de sentidos e por isto, acaba sendo uma das formas de poder mais influentes em nossa sociedade (OLIVEIRA, 2004). 
da cultura. Neste sentido, a autora considera que a mídia, enquanto operadora da Indústria Cultural, se caracteriza como um elemento constituidor dos cotidianos juvenis. Assim, ao mesmo tempo em que a mídia esboça - a partir do lazer - uma possibilidade de fruição, na sua outra face, é também influenciadora no consumo. Entende a autora que o discurso midiático provê de sentidos e significados os cotidianos de forma que não pode ser considerado isoladamente, mas no conjunto das relações e manifestações deste cotidiano. É importante ressaltar que a autora/pesquisadora, considera que uma das possibilidades de se ampliar o debate/ reflexão entre os jovens é a implementação de uma educação para a mídia, principalmente nos contextos escolares. O que está no plano da apropriação, produção de seu conteúdo, dos meios e da leitura/recepção crítica da mídia, gerando assim, conhecimentos técnicos e teóricos que resultam em atividades como produção de vídeo, jornais, programas de rádio, internet entre outros, com isto, estaríamos estimulando os jovens a pensarem e refletirem, autonomamente e de forma esclarecida. Ainda, no campo do lazer, considera que a educação para o lazer também se constitui como uma possibilidade uma vez que prima por valores e experiências lúdicas constituindo a autonomia do sujeito ao considerar seu potencial contraditório e reconhecidamente, libertador (HACK, 2005).

- Scheila Espindola Antunes - "O 'País do Futebol' na Copa do Mundo: Estudo de Recepção ao Discurso Midiático-Esportivo com Jovens Escolares" - Analisou e conheceu o processo de recepção de jovens escolares ao discurso midiático -esportivo durante a Copa do Mundo de 2006 realizada na Alemanha. A constatação é que a escola e a família são suas principais mediações institucionais, assim como foi atribuída à mídia significativa representatividade enquanto mediação tecnológica e tanto a escola como a educação física necessitam repensar suas ações pedagógicas cada vez mais numa perspectiva crítica de formação que não esteja isolada do mundo vivido pelos sujeitos, ou seja, uma educação para a mídia (ANTUNES, 2007);

- Mariana Mendonça Lisboa "Representações do EsporteDa-Mídia na Cultura Lúdica de Crianças" - neste trabalho o objetivo central foi identificar e compreender as representações sociais do esporte-da-mídia na cultura lúdica das crianças e suas possíveis transformações 
quando tematizadas na Educação Física escolar e com isto, quando estimulados os alunos conseguem narrar a dimensão do esporte tele-espetáculo ${ }^{17}$, percebendo os elementos e recursos utilizados em sua veiculação. Contudo, a autora faz um alerta à sociedade/educação em que a escola, através de uma tematização problematizadora, procure nestes férteis espaços de discussão social contribuir para o fortalecimento da recepção crítica dos diferentes assuntos propostos, caso contrário, a simples celebração a-crítica, ou negação dessas temáticas, servirá a perspectivas reproducionistas de muitos discursos e representações colocados pela mídia esportiva (LISBOA, 2007);

- Diego de Souza Mendes - "Luz, Câmara e Pesquisa-Ação: A Inserção da Mídiaeducação na Formação Contínua de Professores de Educação Física" - explorou a temática da formação continuada de Professores de Educação Física a partir da seguinte problemática: Identificar quais os saberes produzidos, incorporados e expressos na prática pedagógica dos professores de Educação Física em relação à mídia. Tendo como estratégia metodológica a perspectiva de projetos de intervenção escolar com a mídia. $\mathrm{O}$ pesquisador percebeu que os professores viam a mídia apenas de forma instrumental e com a pesquisa, ampliou sua visão para objeto de estudo na produção mídiática na escola (MENDES, 2008);

- Cristiano Mezzaroba - "Os Jogos Pan-Americanos Rio/2007 e o Agendamento MidiáticoEsportivo: um Estudo de Recepção com Escolares" - analisou como os jovens percebem, compreendem e analisam o agendamento midiático dos Jogos Pan-Americanos Rio/2007, com possíveis repercussões disso na Educação Física Escolar. Neste estudo, o pesquisador considerou os estudantes como sujeitos-receptores, com os quais o professor de Educação Física pode intervir pedagogicamente. A pesquisa foi realizada numa escola de Florianópolis e neste aspecto, os achados da pesquisa ratificam à necessidade do desenvolvimento do processo de mídia-educação no âmbito escolar, a fim de ampliar as compreensões que envolvem a cultura esportiva dos alunos (MEZZAROBA, 2008);

- Fernando Gonçalves Bitencourt - "Fotografia na Era Digital: Produção, Protagonismo e 
Performance - Problemas para a Educação Física/Ciências do Esporte" - Fez uma crítica, a partir de um estudo etnográfico, no tocante aos usos e abusos da captura de imagens principalmente de desportistas e como o elemento ético/moral é necessário para um momento no qual estamos vivendo de velocidade e difusão da informação via rede, até por que o público e o privado se confundem e, neste aspecto, "o público tornase o lugar de ninguém"! Com isto, ninguém é mais responsável pela implicação de uma imagem veiculada na internet, por exemplo, (BITENCOURT, 2009). Esta é uma questão bastante séria e que vem provocando uma série de debates a partir da Lei de Direito Autoral;

- Dulce M. Cruz, Rafael M. de Albuquerque, Victor de A. Azevedo - "Jogos eletrônicos e o uso de software livre na escola: um relato de experiência" - nesta experiência os autores descrevem a inserção enquanto conteúdo e o uso pedagógico de um jogo eletrônico, a partir do Software Livre, sendo este, motivador para os alunos. No jogo problematizado - LinCityNG- uma cidade é simulada, e o jogador exerce o papel de prefeito. Sua função é a de decidir o que e quando construir, de forma a equilibrar os diversos interesses e necessidades da população: empregos, luz, água, segurança, educação, lazer, sistema viário, oferta de produtos e serviço de emergência contra incêndio, entre outros. O desenvolvimento da cidade depende de construções relacionadas à educação, cultura e tecnologia, que possibilitam que se produzam construções mais avançadas, como fábricas e termoelétricas, ao longo do jogo. Painéis com índices e gráficos sobre a condição da cidade ajudam o jogador a decidir o que é necessário fazer para melhorar o funcionamento. Esta estratégia metodológica de ensino auxiliou na proposição e na construção - em parceria com a professora da escola - de uma proposta que incluísse o jogo como conteúdo adequado para as suas aulas, buscando um bom aproveitamento pedagógico (CRUZ et al, 2009);

- Rogério Santos Pereira - "Avatares no Second Life: corpo e movimento na constituição da noção de pessoa on-line." Esta pesquisa traz reflexões sobre o conceito do que é virtual em busca do rompimento da oposição dualística com o real e configura-se em uma experiência, de certa forma, inédita na Educação Física no Brasil, pois problematiza a relação corpo e movimento no ciberespaço 
a partir do jogo de computador Second Life. Neste sentido, discorre também sobre as possíveis aproximações das tecnologias digitais - em especial dos jogos eletrônicos - com a Educação Física. O pesquisador percorreu o sentido do "ser" on-line, a partir da "Antropologia no ciberespaço", compreendendo o corpo como uma construção simbólica e o ciberespaço como uma das dimensões constituintes das sociedades complexas. A partir das observações, percebeu que os conceitos de imaginação e imaginário são essenciais para entender como os participantes tecem caminhos em suas brincadeiras narrativas para construir no ciberespaço uma corporalidade que é central em suas interações. É importante ressaltar que o sentido atribuído ao avatar ${ }^{18} \mathrm{e}$ dos demais objetos do Second Life só pode ser dado a partir das ações dos participantes no jogo o que esboça então, as intencionalidades numa rede de relações e suas ações são condição para que a relação exista. As brincadeiras narrativas traçadas pelos participantes constituem as identidades aceitas e reconhecidas pelos grupos no ciberespaço (PEREIRA, 2009).

Como vimos estes trabaIhos, entre tantos outros, tencionam a relação mídia (Tecnologia)-Educação Física, no entanto, acredito que o principal aspecto emancipatório - que está presente em todos os trabalhos - que deveria ter sido mais observado na comunidade acadêmica, na sociedade de modo geral, é o "sentido" atribuído a uma educação para mídia, ou mesmo da tecnologia como uma "potência" no aspecto pedagógico - ou melhor, ainda: $\mathrm{O}$ de estabelecer um permanente processo de mudança cultural em que as pessoas - alunos - sociedade em geral aprendam a compartilhar, a colaborar umas com as outras.

Os trabalhos/experiências apontam para uma reflexão no trato com a mídia e a tecnologia sob o prisma da Educação/Educação Física. Do simples manuseio de equipamentos, passando pelo olhar atendo dos sujeitos que recebem as mensagens dos veículos de comunicação à dimensão lúdica nos campos do lazer, esporte, entretenimento e do

18 Em informática, avatar é a representação visual de um utilizador em realidade virtual. De acordo com a tecnologia, pode variar desde um sofisticado modelo 3D até uma simples imagem. São normalmente pequenos, de tamanhos variados mas deixando espaço livre para a função principal do site, programa ou jogo que se está a usar. Em um mundo virtual, um avatar é um personagem digital que você pode criar e personalizar. É você - apenas em 3D. um avatar que se assemelha a sua vida real ou criar uma identidade alternativa, é a imaginação, quem você quiser ser! www. wikipedia.org. Acesso em 04/10/2010. 
ciberespaço, ratificam que nenhum segmento da sociedade - em especial a Educação Física - deva ficar de fora da apropriação, reflexão crítica dos meios de comunicação e das tecnologias de informação. Bem como, urge articular o sentido do SL e as experiências com a Educação Física para uma mudança de comportamento das pessoas na sociedade e com isto, expandir o conhecimento e o compartilhamento. Para Lima et al (2009, p.165) "o que se produz é comum, e o comum que compartilha serve de base para a produção futura, numa relação expansiva em espiral".

Percebe-se então, que o processo de apropriação, criação e recriação da mídia e das tecnologias no âmbito da Educação Física, já se configurou como um marco na pauta de discussão da pesquisa e intervenção. Mas, algumas questões, a meu ver, mereçam importância no contexto educacional, político e cultural (sem querer respondêlas, mas pelo menos persegui-las): E ai?! O que aconteceu depois que estas pesquisas foram realizadas? Será que a semente (ou o "sentido" como estou discutindo aqui neste artigo) fora plantada e germinada? Houve uma mudança - na cultura - em sociabilizar o conhecimento e oportunizar os alunos/sociedade a apropriarem-se com autonomia das Tic's? Deixo estas questões em aberto para pensá-las no sentido de que não podemos abandoná-las e sim, que elas constituam-se em nossa utopia.

[...] as formas de produção colaborativas criam novos modos de organização social e econômica, com impacto profundo nas formas de produção e organização do conhecimento, da informação e dos bens culturais (LIMA et al p.164).

\section{Considerações (In) conclusivas}

A velocidade com que as tecnologias são criadas e neste aspecto, transformam o modo de ser e estar no mundo na contemporaneidade, é impressionante. A todo instante nasce uma nova tecnologia - comunicacional/informacional/digital - e como ela, uma nova forma de relacionar-se o que gera/germina uma nova narrativa. Impressiona como qualquer tentativa de prever fica ultrapassada pelo novo. Adorno e Horkheimer (1985) já diziam que o novo nasce velho no bojo do processo de Indústria Cultural. Talvez este seja o entrave para que haja uma maior apropriação das tecnologias pela humanidade, pois o caráter mercadoria ainda está muito presente em nossas relações.

Seria ingênuo não perceber que a tecnologia recebe o estigma 
de quem a criou e assim as forças econômicas, políticas e simbólicas produzem-na sob um prisma ideológico e reforçam os valores de uma sociedade. O software livre e com ele as diversas manifestações a seu favor, produzem uma nova forma de lidar com este determinismo, uma nova narrativa, pois tem como matriz geradora, a colaboração e com isso, uma nova (re) configuração da sociedade faz surgir. Ainda, o SL é notável por usar e fazer usar a inteligência de modo compartilhado para apreensão e produção do conhecimento e este sendo redistribuído à sociedade. Estou ciente que não devemos nos iludir como alerta Bolaño (2007) com este potencial advindo da internet, por exemplo, até por que ainda encontra-se nas mãos das organizações econômicas o capital que gerencia este potencial. No entanto, o caráter democratizador da informação e promotor de uma comunicação horizontalizada provoca uma autonomia na sociedade e pode ser geradora de uma ação contra-hegemônica aos ditames de uma economia monopolista.

Na verdade, nada é unívoco no desenvolvimento capitalista e os mesmos fatores que o impulsionam abrem também possibilidades de ação transformadora [...]. Não obstante, o surgimen- to da internet coloca na ordem do dia a questão solidária da sociedade civil e de suas organizações na busca de um ordenamento social mais justo e de maior autonomia em relação ao capital e ao Estado. Nesse sentido, a internet é uma promessa de comunicação global interativa, criadora de comunidade. (BOLAÑO, 2007 p. 47).

A partir da própria dinâmica/velocidade em que o mercado midiático e tecnológico faz surgir novos aparelhos celulares, percebese uma tendência em se estabelecer uma convergência possível das tecnologias. Ou seja, uma tecnologia que dê conta de reunir todas as mídias possíveis e conhecíveis até o momento. O celular aparece com esta função, mas de forma muito tímida. Seu uso já é multifacetado, do simples falar às interações mais diversas no campo do entretenimento, comunicação (áudio-visual) entre tantos. Seu acesso - aspecto importante no processo de interação - já tende a ser maior, atingindo a maioria da sociedade, tendo em vista o barateamento de sua produção e com o SL também na sua construção isto se ampliará.

Sobre este aspecto é que o campo educacional, principalmente no ambiente escolar, precisa está atento a estas mudanças significa- 
tivas no âmbito da tecnologia, pois isto implicará mudanças no modo de ensinar-aprender-ensinar e produzir conhecimento. Observo que isto já vem acontecendo, ou seja, já há uma preocupação do impacto das tecnologias e da mídia na educação, no entanto, ainda carece de mais ações no tocante a esfera pública para que não fique distante a relação escola-tecnologia e prolifere um espaço de tensão permanente.

No campo da Educação Física, especificamente no trato com as Tic's e da (re) significação da mídia, compreendo que se precise não só fazer uso, mas necessariamente, germinar o "sentido" da colaboração entre os atores sociais (os sujeitos que estão no campo de observação) e os profissionais da área. Talvez assim, este "bicho papão" (tecnologia/mídia) não assuste tanto, pois será sempre um aliado à emancipação e autonomia. Experiências com o celular - que está presente na vida dos alunos - podem constituir-se em um potencial criativo sem fronteiras.

\section{Referências}

ADORNO. T.W. \& HORKHEIMER, $M$. Dialética do esclarecimento. Rio de Janeiro: Jorge Zahar, 1985.
ANTUNES, Scheila Espindola. O "país do futebol" na copa do mundo: estudo de recepção ao discurso midiático-esportivo com jovens escolares. Florianópolis/SC. Dissertação de Mestrado, 2007.

BACON, Francis. Nova atlântida. Tradução: José Aluysio Reis de Andrade. São Paulo: Nova cultural, 2000.

BENKLER. Yochai. Saber comum: produção de materiais educacionais entre pares. Salvador/BA, Revista da FACED/ UFBA, (no prelo), 2010.

BITENCOURT, Fernando Gonçalves. Fotografia na era digital: produção, protagonismo e performance - problemas para a educação física/ciências do esporte. XVI Congresso Brasileiro de Ciências do Esporte,; III Congresso Internacional de Ciências do Esporte. Anais... Salvador/Bahia, 20 a 25 de setembro de 2009.

BOLAÑO, César et. al. Economia política da Internet. São Cristóvão: Editora da UFS, 2007.

BRANT, João. O lugar da educação no confronto entre colaboração e competição. In: PRETTO, N. De L. e SILVEIRA, S. A. (Orgs). Além das redes de colaboração: internet, diversidade cultural e tecnologias do poder. S. A. Salvador: EDUFBA, 2008. p. 69-74. 
CASTELLS, M. A sociedade em rede: a era da informação - economia, sociedade e cultura. Tradução: Roneide Venâncio Majer. São Paulo: Paz e Terra, 1999.

CRUZ, Dulce M. et al. Jogos eletrônicos e o uso de software livre na escola: um relato de experiência. Simpósio Brasileiro de Informática na Educação, 20, Anais... Florianópolis: UFSC, 2009.

HACK, Cássia. Lazer e mídia em culturas juvenis: uma abordagem da vida cotidiana. Florianópolis/ SC. Dissertação de Mestrado, 2005.

HIMANEN, Pekka. A ética dos HACKERS e o espírito da era da informação: a importância dos exploradores da era digital. Tradução: Fernanda Wolff. Rio de Janeiro: Campus, 2001.

HUXLEY, Aldous. Admirável mundo novo. Tradução: Lino Vallandro e Vidal Serrano. São Paulo: GLOBO, 2001.

JENKINS Henry. Cultura da Convergência. Tradução de Susana Alexandria. São Paulo: Aleph, 2009.

LEMOS, André. Ciberespaço e tecnologias móveis processos de territorialização e desterritorialização na cibercultura. Disponível em: www.facom.ufba.br/ ciberpesquisa/andrelemos/ territorio. Acesso em: $10 \mathrm{de}$ abril de 2010.

LIMA, Clovis R. M. de. et al. Trabalho imaterial, produção cultural colaborativa e economia da dávida. Rio de Janeiro. Liinc em Revista, v.5, $\mathrm{n}^{\circ} 2$, setembro, 2009.

LISBÔA, Mariana Mendonça. Representações do esporteda-mídia na cultura lúdica de crianças. Florianópolis/SC. Dissertação de Mestrado, 2007. MENDES, Diego de Sousa. Luz, Câmara e Pesquisa-Ação: $A$ Inserção da Mídiaeducação na Formação Contínua de Professores de Educação Física. Florianópolis/SC. Dissertação de Mestrado, 2008.

MEZZAROBA, Cristiano. Os jogos pan-americanos rio/2007 e o agendamento midiáticoesportivo: um estudo de recepção com escolares. Florianópolis/SC. Dissertação de Mestrado, 2008. KENSKI, Vani Moreira. Educação e tecnologias: o novo ritmo da informação. Campinas: PAPIRUS, 2007.

OLIVEIRA, Marcio Romeu Ribas de. O Primeiro olhar: Experiência com Imagens na Educação Física Escolar. Florianópolis, Dissertação de Mestrado, UFSC, 2004.

PEREIRA, Rogério Santos. Second life: o lazer em um ambiente de sociabilidade na internet. 
XV Congresso Brasileiro de Ciências do Esporte; II Congresso Internacional de Ciências do Esporte. Anais... Recife, setembro de 2009.

- Avatares no Second

Life: corpo e movimento na constituição da noção de pessoa on-line. Florianópolis/SC. Dissertação de Mestrado, 2009. PRETTO, Nelson De Luca e ASSIS, Alessandra. Cultura digital e educaçao: redes já! In: PRETTO, N. De L. e SILVEIRA, S. A (Orgs). Além das redes de colaboração: internet, diversidade cultural e tecnologias do poder. Salvador: EDUFBA, 2008. p. 75-84.

SANTOS, Cássia Fernanda Cardoso dos. A Mídia nas Aulas de Educação Física: Uma possibilidade. XV Congresso Brasileiro de Ciências do Esporte; II Congresso Internacional de Ciências do Esporte. Anais... Recife, setembro de 2009.

SIMON, I e VIEIRA, M. S. O rossio não-rival. In: PRETTO, N. De L. e SILVEIRA, S. A. (Orgs). Além das redes de colaboração: internet, diversidade cultural e tecnologias do poder. Salvador: EDUFBA, 2008. p. 15-30.

SILVEIRA, Sérgio Amadeu da. Convergência digital, diversidade cultural e esfera pública. In: PRETTO, N. De L. e SILVEIRA, S. A. (Orgs). Além das redes de colaboração: internet, diversidade cultural e tecnologias do poder. Salvador: EDUFBA, 2008. p. 31-50.

. Software livre: a luta pela liberdade do conhecimento. São Paulo: Perseu Abramo, 2004.

TAS, Marcelo. Para um bom uso das novas ferramentas, observem as crianças. In: PRETTO, N. De L. e SILVEIRA, S. A. (Orgs). Além das redes de colaboração: Internet, diversidade cultural e tecnologías do poder. Salvador: EDUFBA, 2008. p. 201-209.

THOMPSON, John B. A Mídia e a modernidade: Uma teoria social da mídia. Tradução: Wagner de Oliveira Brandão. Petrópolis/RJ: Vozes, 1998.

Recebido: setembro/2010. Aprovado: outubro/2010. 